\title{
Tensile properties of novel carbon/glass hybrid thermoplastic composite rods under static and fatigue loading
}

\author{
${ }^{1}$ Polymer matrix hybrid composite materials group, National Institute for Materials Science (NIMS) - 1-2-1 Sengen, \\ Tsukuba, Ibaraki, 305-0047 Japan \\ e-mail: NAITO.Kimiyoshi@nims.go.jp \\ e-mail: OGUMA.Hiroyuki@nims.go.jp
}

\begin{abstract}
Novel carbon/glass hybrid thermoplastic composite rods have been developed consisting of a PAN-based carbon fiber, an E-glass fiber, and a thermoplastic matrix. Three types of hybrid rods with different carbon/glass ratios were then fabricated. The surface and cross-sectional morphologies of the hybrid rods were observed using a digital microscope. Additionally, the volume fractions of carbon/glass fibers, matrix, and void were determined by specific gravity measurements and thermogravimetric analyzes. The glass fibers in the hybrid rods display a braided structure of the $2 / 2$ twill weave. The braid angle (defined as the orientation angle of the interlacing yarns with respect to the longitudinal axis of the rod) ranged from $22.3^{\circ}$ to $35.2^{\circ}$. The various volume fractions were in the ranges of $24.6-46.2 \%$ for the carbon fiber, $23.2-39.8 \%$ for the glass fiber, $23.4-25.5 \%$ for the matrix, and $7.3-10.2 \%$ for the voids. The tensile properties and fracture behavior of the hybrid rods under static and fatigue loading were also investigated. For the static tests, the stress applied to the specimen was nearly linearly proportional to the strain until the failure of all-hybrid rods. The tensile modulus, strength, and failure strain of the hybrid rods were measured in the ranges of 65-91GPa, 1.42-1.84 GPa, and 2.1-2.2\%, respectively. The tensile modulus and strength increased as the volume fraction of the carbon fiber increased. However, the failure strain decreased as the volume fraction of the carbon fiber increased. For fatigue tests, the maximum applied stress-number of cycles to failure (S-N) curves for all-hybrid rods were obtained from 0.1 of the stress ratio (minimum/maximum stress) and $10 \mathrm{~Hz}$ of the loading frequency. The fatigue strength at $10^{7}$ cycles for all-hybrid rods was less than $30 \%$ of ultimate breaking stress. The fatigue performance of the hybrid rods was significantly lower than that of conventional carbon fiber reinforced polymer matrix composites and steel rods. The voids in the hybrid rods affected the fatigue tensile properties.
\end{abstract}

\section{INTRODUCTION}

Tendons are widely used as tension members for constructing civil, building, and offshore engineering infrastructure. For the fields of civil and building engineering structures, prestressed concrete is the primary construction material for beams and floors in traffic road bridges and piers (automotive, train), floors in high rise buildings as well as cylindrical walls and spherical shells in tanks [1]. Within the field of offshore engineering, prestressed concrete is also the primary construction material used in fixed and floating concrete platforms [2].

Tendons and traditional reinforced concrete used in high-tensile-strength steel wires, bars, and rebars. Corrosion and fatigue of steel cables and classical steel reinforcing bars are serious issues [3]. Therefore, the use of fiber-reinforced polymer matrix composites (fiber-reinforced plastics), particularly carbon fiber reinforced polymer matrix composites [carbon fiber reinforced plastics (CFRPs)] have been proposed [4]. The application of CFRPs in construction, particularly in post-strengthening and rehabilitation, is well known and highly appreciated in most applications due to its long-term reliability.

In addition, as the oil and gas industries move to explore and develop ultra-deepwater reservoirs, the weight and performance of critical systems are increasingly important [5]. Generally, high-tensile-strength steel tubes are used for the tendons. The tubes become increasingly heavy at ultra-deepwater depths due to the requirement to resist collapse. CFRPs, having the advantage of being stronger and lighter than steel, will provide alternatives for ultra-deepwater projects since the weight-savings of the components provides a 
significant operational improvement [5].

Epoxy resins are frequently used as a matrix in CFRPs because they have excellent mechanical properties and good handling properties during fabrication. Currently, thermosetting epoxy resins are most often used for CFRP tendons [6]. However, the inherently brittle nature of epoxy and other thermosetting polymers as well as their poor resistance to crack initiation and growth are important issues that largely limit their application in certain fields. Epoxy resins are also generally neither fusible nor soluble after curing due to the presence of cross-links in the chemical structure of cured resin. This property significantly restricts the possibility of post-forming, recycling, or reusing.

In contrast, carbon-fiber-reinforced thermoplastic matrix composites (carbon fiber reinforced thermoplastics, CFRTPs) have great potential to be post-formed, recycled, and reused because thermoplastic resins are toughened and fusible. However, the manufacturing of CFRTPs usually requires significantly more energy because of the higher temperatures and pressures necessary for the impregnation process due to the higher molecular weight [7]. A new resin that has both good workability during thermosetting as well as post-formability, recyclability, or reusability has been desired for use as the CFRTP matrix.

A new thermoplastic epoxy resin has been recently developed by Nagase ChemteX Corporation [8]. Additionally, novel carbon/glass hybrid thermoplastic composite rods called "CABKOMA" have been developed by Komatsu Seiren Co., Ltd. The hybrid rods are a core-in-sheath type and consist of a bundle (or bundles) of carbon fiber surrounded by an outer braided bundle glass fiber in which a new thermoplastic epoxy resin is evenly impregnated as the matrix. The new thermoplastic epoxy resin remains thermoplastic even after curing.

In the present work, fundamental research on novel carbon/glass hybrid thermoplastic composite rods was carried out. The morphology and tensile properties of the novel carbon/glass hybrid thermoplastic composite rods were evaluated. The longitudinal and cross-sectional morphology of the hybrid rods were observed using a digital microscope. The volume fractions of the carbon fiber, glass fiber, matrix, and voids for the hybrid rods were estimated using a thermogravimetric analysis and specific gravity measurement via ethanol immersion. Static tensile tests of the novel carbon/glass hybrid thermoplastic composite rods were performed. The Weibull statistical distributions of the tensile strength for the hybrid rods were then examined. Fatigue properties were also investigated based on the cyclic load testing.

\section{MATERIALS AND METHODS}

\subsection{Materials}

The novel carbon/glass hybrid thermoplastic composite rods have been developed by the Komatsu Seiren Co., Ltd. Three types of the hybrid rods were fabricated, described as 24K1P, 24K2P, and 24K3P with dissimilar carbon/glass ratios. The hybrid rods were the core-sheath type. The carbon fiber bundle (core) surrounded the glass fiber tubular membrane by adding a glass fiber bundle with a braid structure (sheath) in which the thermoplastic epoxy was evenly infiltrated as a matrix.

\subsection{Characterization}

The longitudinal morphology (in the plane view) of the hybrid rods was observed using a digital microscope (VHX-5000 and VH-ZST, Keyence). The hybrid rods were cut into approximately $10 \mathrm{~mm}$ lengths using a rotary cutting machine. The specimen for transverse sectional view was embedded in an epoxy resin molding material, and then cut and polished along the transverse section. The cross-sectional morphology of the hybrid rods was also observed using a digital microscope (VHX-5000 and VH-ZST, Keyence).

The densities of the hybrid rods, $\rho_{h}$, (approximately $50 \mathrm{~mm}$ in length) were measured via ethanol immersion (ASTM D792) [9]. The densities of the carbon fiber, $\rho_{C F}$, glass fiber, $\rho_{G F}$, and matrix, $\rho_{M}$ were $1.80 \mathrm{~g} / \mathrm{cm}^{3}, 2.54 \mathrm{~g} / \mathrm{cm}^{3}$, and $1.20 \mathrm{~g} / \mathrm{cm}^{3}$, respectively. At least three all-hybrid rod specimens were tested.

Thermogravimetric analysis (TGA) tests of the hybrid rods (approximately $5 \mathrm{~mm}$ in length) were performed in the temperature ranges of $30-1000{ }^{\circ} \mathrm{C}$ at a heating rate of $10{ }^{\circ} \mathrm{C} / \mathrm{min}$ in a $\mathrm{N}_{2}(400 \mathrm{~mL} / \mathrm{min}), \mathrm{Ar}$ $(400 \mathrm{~mL} / \mathrm{min})^{1}$, and $\mathrm{N}_{2} / \mathrm{O}_{2}=4 / 1(400 / 100 \mathrm{~mL} / \mathrm{min})$ atmosphere using a simultaneous thermogravimetric analyzer (STA7300, Hitachi High-Tech Science Corporation). At least three all-hybrid rod specimens were tested for under each condition.

\footnotetext{
${ }^{1}$ TGA behavior of the hybrid rods was checked in both $\left(\mathrm{Ar}\right.$ and $\mathrm{N}_{2}$ ) inert atmosphere, because the materials (especially, metals and ceramics) are sometimes reacted in $\mathrm{N}_{2}$ gas.
} 


\subsection{Static test}

The hybrid rods were trimmed to $250 \mathrm{~mm}$ for the $24 \mathrm{~K} 1 \mathrm{P}, 350 \mathrm{~mm}$ for the $24 \mathrm{~K} 2 \mathrm{P}$, and $450 \mathrm{~mm}$ for the 24K3P. The glass fabric/epoxy composite tabs were fabricated using a wet hand layup process applied to each end of the specimen [10]. Additionally, a gage length, $L$, of $110 \mathrm{~mm}$ was used. The tests were conducted based on ASTM D3039 [11]. The specimen was installed in the testing machine using an active gripping system. The tensile tests of the hybrid rods were performed using a universal testing machine (Autograph AG-series, Shimadzu) with a $50 \mathrm{kN}$ load cell. A crosshead speed of $1 \mathrm{~mm} / \mathrm{min}$ was applied. All tests were conducted under laboratory environment conditions at room temperature (at $(23 \pm 3){ }^{\circ} \mathrm{C}$ and $(50 \pm 5) \%$ relative humidity). Ten all-hybrid rod specimens were tested.

\subsection{Fatigue test}

The hybrid rods were trimmed to $190 \mathrm{~mm}$ for the $24 \mathrm{~K} 1 \mathrm{P}, 250 \mathrm{~mm}$ for the $24 \mathrm{~K} 2 \mathrm{P}$, and $310 \mathrm{~mm}$ for the 24K3P. The glass fabric/epoxy composite tabs were fabricated using a wet hand layup process applied to each end of the specimen. Additionally, a gage length, $L$, of $50 \mathrm{~mm}$ was used. The tests were conducted based on ASTM D3479 [12]. The specimen was installed in the testing machine using a hydraulic operated chuck system. Fatigue tests were conducted using a servo-hydraulic testing machine at a frequency of $10 \mathrm{~Hz}$ under cyclic loading with constant amplitude. For the 24K1P rod, an MTS 858 Mini Bionix with a $25 \mathrm{kN}$ load cell was used. For the 24K2P/24K3P rods, a Shimadzu Servopulser EHF-E series with a $50 \mathrm{kN}$ load cell was used. The waveform of cyclic loads was sinusoidal. The load/stress ratio, $\mathrm{R}$, of the minimum load to the maximum load/stress was 0.1 . The fatigue tests were terminated after $1 \times 10^{7}$ cycles.

\section{RESULTS}

\subsection{Characterization}

Typical longitudinal images of the hybrid rods clearly show that the glass fibers in the hybrid rods are of a braid structure (Figure 1). The biaxial construction has two sets of yarns running in opposite directions, where the yarns in one direction are passing under and over the other. The braid interlacement patterns are very similar to woven structures discussed in [13]. The braids were observed to have a $2 / 2$ twill weave.

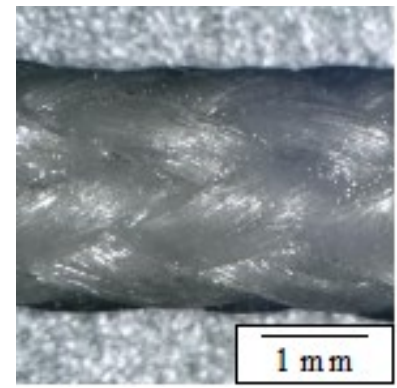

(a) $24 \mathrm{~K} 1 \mathrm{P}$

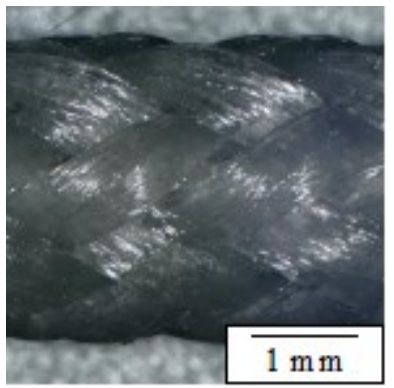

(b) $24 \mathrm{~K} 2 \mathrm{P}$

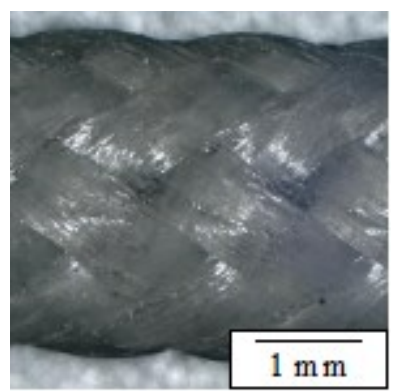

(c) $24 \mathrm{~K} 3 \mathrm{P}$

Figure 1: Typical longitudinal images of the hybrids rods.

The braid angle $(\theta)$ is the orientation angle of the interlacing yarns with respect to the braid axis. The braid angles of the hybrid rods were measured by taking their image under the digital microscope. The average values for $\theta$ were $22.3^{\circ}$ for the $24 \mathrm{~K} 1 \mathrm{P}, 30.2^{\circ}$ for the $24 \mathrm{~K} 2 \mathrm{P}$, and $35.2^{\circ} 24 \mathrm{~K} 3 \mathrm{P}$, respectively (The results are shown in Table 1).

Table 1: Physical and mechanical properties of the carbon/glass hybrid thermoplastic composite rods.

\begin{tabular}{l|l|l|l|l|l|l}
\hline & 24K1P & 24K2P & 24K3P & $\begin{array}{l}\text { ALUMINUM } \\
\text { ALLOY }\end{array}$ & $\begin{array}{l}\text { HIGH } \\
\text { STRENGTH } \\
\text { STEEL }\end{array}$ \\
\hline CHARACTERIZATION & $22.3(1.6)$ & $30.2(1.5)$ & $35.2(1.8)$ & & \\
\hline Braid angle, $\theta\left(^{\circ}\right)$ & $1.759(0.007)$ & $1.737(0.008)$ & $1.698(0.009)$ & 2.7 & 7.8 \\
\hline Density, $\rho_{h}\left(\mathrm{~g} / \mathrm{cm}^{3}\right)$ &
\end{tabular}




\begin{tabular}{l|l|l|l|l|l}
\hline Weight fraction of carbon fiber, $W_{C F}(\%)$ & 25.29 & 39.74 & 49.00 & & \\
\hline Weight fraction of glass fiber, $W_{G F}(\%)$ & 57.33 & 43.31 & 24.52 & & \\
\hline Weight fraction of matrix, $W_{M}(\%)$ & 17.38 & 16.95 & 16.48 & & \\
\hline Volume fraction of carbon fiber, $V_{C F}(\%)$ & $24.58(1.20)$ & $38.34(0.68)$ & $46.18(2.79)$ & & \\
\hline Volume fraction of glass fiber, $V_{G F}(\%)$ & $39.75(0.79)$ & $29.63(0.41)$ & $23.15(1.93)$ & & \\
\hline Volume fraction of matrix, $V_{M}(\%)$ & $25.49(0.37)$ & $24.54(0.32)$ & $23.39(0.67)$ & & \\
\hline Volume fraction of void, $V_{V}(\%)$ & $10.18(0.76)$ & $7.49(0.60)$ & $7.28(1.33)$ & & \\
\hline
\end{tabular}

\section{STATIC}

\begin{tabular}{l|l|l|l|l|l}
\hline Tensile modulus, $E(\mathrm{GPa})$ & $65(3)$ & $87(7)$ & $91(7)$ & 70 & 210 \\
\hline Tensile strength, $\sigma_{u l t}(\mathrm{GPa})$ & $1.42(0.05)$ & $1.80(0.06)$ & $1.84(0.05)$ & 0.60 & 2.00 \\
\hline Failure strain, $\varepsilon_{\text {ult }}(\%)$ & $2.18(0.07)$ & $2.13(0.15)$ & $2.08(0.14)$ & & \\
\hline Calculated tensile modulus, $E_{(C A L 2)}(\mathrm{GPa})$ & 69 & 92 & 106 & & \\
\hline Calculated tensile strength, $\sigma_{\text {ult }(C A L)}(\mathrm{GPa})$ & 1.41 & 1.91 & 2.19 & & \\
\hline Weibull modulus, $m$ & 23.77 & 27.29 & 32.50 & & \\
\hline
\end{tabular}

\section{FATIGUE}

\begin{tabular}{l|l|l|l|l|l}
\hline Intercept (power law model), $a$ & 1.829 & 1.869 & 1.947 & & \\
\hline Slop (power law model), $b$ & -0.1169 & -0.0845 & -0.0843 & & \\
\hline
\end{tabular}

() indicate standard deviations

Typical cross-sectional images of the hybrid rods clearly show that the individual carbon and glass fibers are well dispersed in the thermoplastic epoxy matrix (Figure 2). Some partial voids were observed at four sites at the boundary between the carbon fiber and glass fiber components.

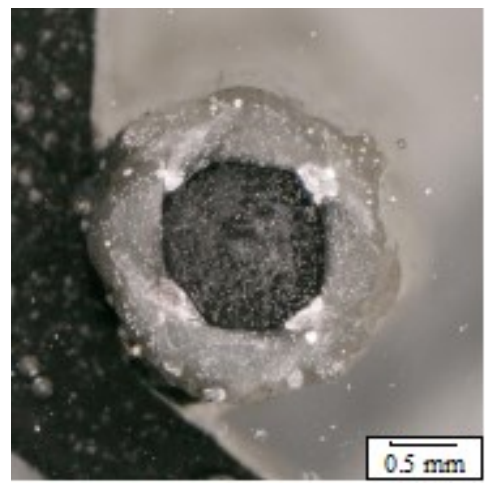

(a) $24 \mathrm{~K} 1 \mathrm{P}$

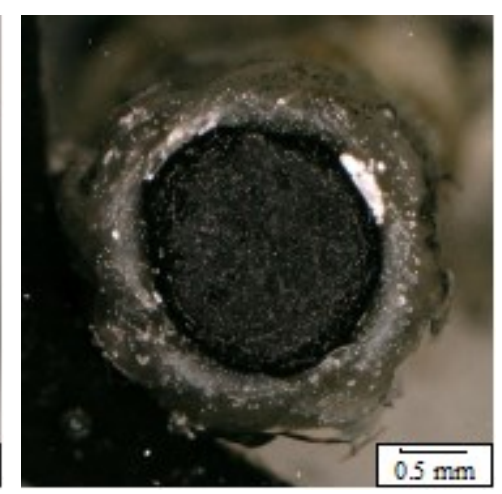

(b) $24 \mathrm{~K} 2 \mathrm{P}$

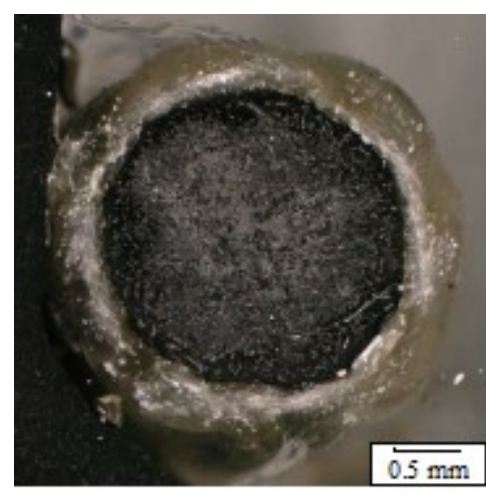

(c) $24 \mathrm{~K} 3 \mathrm{P}$

Figure 2: Typical cross-sectional images of the hybrids rods.

The densities of the hybrid rods were measured via ethanol immersion per ASTM D792 [9]. The average values for $\rho_{h}$ were $1.759 \mathrm{~g} / \mathrm{cm}^{3}$ for the $24 \mathrm{~K} 1 \mathrm{P}, 1.737 \mathrm{~g} / \mathrm{cm}^{3}$ for the $24 \mathrm{~K} 2 \mathrm{P}$, and $1.698 \mathrm{~g} / \mathrm{cm}^{3}$ for the 24K3P, respectively (The results are shown in Table 1).

TGA was employed to estimate the weight fraction of the hybrid rods. The TGA of the hybrid rods under a $\mathrm{N}_{2} / \mathrm{O}_{2}$ atmosphere show a weight loss of $42.67 \%$ for the $24 \mathrm{~K} 1 \mathrm{P}, 56.69 \%$ for the $24 \mathrm{~K} 2 \mathrm{P}$, and $65.48 \%$ for the $24 \mathrm{~K} 3 \mathrm{P}$ for the temperature range of $900-1000{ }^{\circ} \mathrm{C}$. This implies the weight fraction (i.e., weight content) of the glass fiber, $W_{G F}$, is $57.33 \%$ for the $24 \mathrm{~K} 1 \mathrm{P}, 43.31 \%$ for the $24 \mathrm{~K} 2 \mathrm{P}$, and $24.52 \%$ for the $24 \mathrm{~K} 3 \mathrm{P}$.

The TGA of the hybrid rods under both $\mathrm{N}_{2}$ and Ar atmospheres show a weight loss of $17.38 \%$ for the $24 \mathrm{~K} 1 \mathrm{P}, 16.95 \%$ for the $24 \mathrm{~K} 2 \mathrm{P}$, and $16.48 \%$ for the $24 \mathrm{~K} 3 \mathrm{P}$ for the temperature range of $900-1000{ }^{\circ} \mathrm{C}$. This implies the weight fraction of the glass fiber, $W_{G F}$, and the carbon fiber, $W_{C F}$, are $82.62 \%$ for the $24 \mathrm{~K} 1 \mathrm{P}$, $83.05 \%$ for the $24 \mathrm{~K} 2 \mathrm{P}$, and $83.52 \%$ for the $23 \mathrm{~K} 3 \mathrm{P}$. By subtracting the TGA results, the weight fraction of the carbon fiber, $W_{C F}$, was $25.29 \%$ for the $24 \mathrm{~K} 1 \mathrm{P}, 39.74 \%$ for the $24 \mathrm{~K} 2 \mathrm{P}$, and $49.00 \%$ for the $24 \mathrm{~K} 3 \mathrm{P}$. Additionally, the weight fraction of the matrix, $W_{M}$, was $17.38 \%$ for the $24 \mathrm{~K} 1 \mathrm{P}, 16.95 \%$ for the $24 \mathrm{~K} 2 \mathrm{P}$, and $16.48 \%$ for the $24 \mathrm{~K} 3 \mathrm{P}$. The TGA results are summarized in Table 1. 
The volume fractions for the carbon fiber, $V_{C F}$, glass fiber, $V_{G F}$, matrix, $V_{M}$, and void, $V_{V}$ in each hybrid rods were calculated based on ASTM D2734 [14], and the equations are given by:

$$
\begin{aligned}
& V_{C F}=\frac{W_{C F} \cdot \rho_{h}}{\rho_{C F}} \\
& V_{G F}=\frac{W_{G F} \cdot \rho_{h}}{\rho_{G F}} \\
& V_{M}=\frac{W_{M} \cdot \rho_{h}}{\rho_{M}} \\
& V_{V}=1-V_{C F}-V_{G F}-V_{M}
\end{aligned}
$$

The average values of $V_{C F}, V_{G F}, V_{M}$, and $V_{V}$ were $24.58 \%, 39.75 \%, 25.49 \%$, and $10.18 \%$ for the $24 \mathrm{~K} 1 \mathrm{P} ; 38.34 \%, 29.63 \%, 24.54 \%$, and $7.49 \%$ for the $24 \mathrm{~K} 2 \mathrm{P}$, and $46.18 \%, 23.15 \%, 23.39 \%$, and $7.28 \%$ for the $24 \mathrm{~K} 3 \mathrm{P}$, respectively (The results are shown in Table 1).

The volume fraction of the voids for the hybrid rods was 5-10 times higher than that of conventional carbon fiber reinforced thermosetting polymer (epoxy) matrix composites.

\subsection{Static test}

Figure 3 shows the typical tensile stress-strain $(\sigma-\varepsilon)$ curves for the hybrid rods. For the all-hybrid rods, the stress applied to the specimen was linearly proportional to the strain until failure.

The tensile modulus, $E$, is calculated using a least square method for the straight-line section of the tensile stress-strain curve. The average values for the tensile modulus, $E$, for the hybrid rods were found to be $65 \mathrm{GPa}$ for the $24 \mathrm{~K} 1 \mathrm{P}, 87 \mathrm{GPa}$ for the $24 \mathrm{~K} 2 \mathrm{P}$, and $91 \mathrm{GPa}$ for the $24 \mathrm{~K} 3 \mathrm{P}$, respectively (The results are shown in Table 1).

The average values for the tensile strength, $\sigma_{u l t}$, and failure strain, $\varepsilon_{u l t}$, for the hybrid rods were 1.42 $\mathrm{GPa}$, and $2.18 \%$ for the $24 \mathrm{~K} 1 \mathrm{P} ; 1.80 \mathrm{GPa}$ and $2.13 \%$ for the $24 \mathrm{~K} 2 \mathrm{P}$; and $1.84 \mathrm{GPa}$ and $2.08 \%$ for the 24K3P, respectively (The results are shown in Table 1).

The tensile modulus and strength increased with an increase in $V_{C F}$. However, the failure strain was approximately equivalent among the hybrid rods.

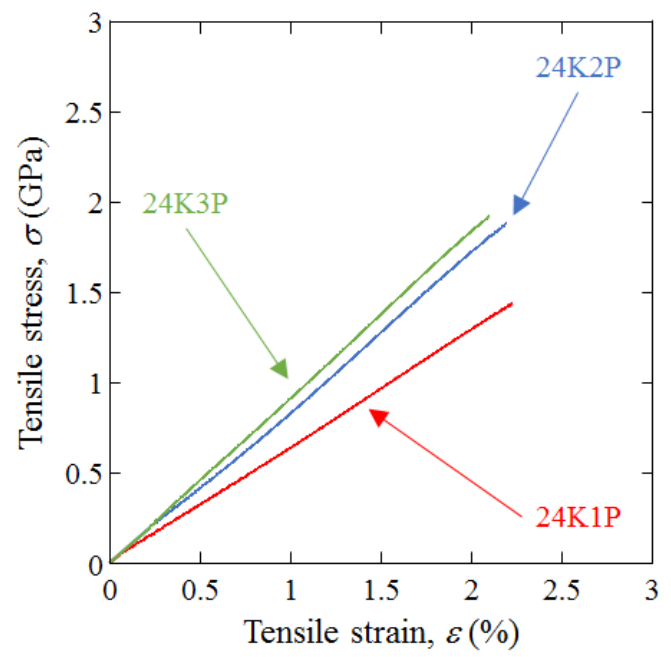

Figure 3: Typical tensile stress-strain $(\sigma-\varepsilon)$ curves for the hybrid rods.

\subsection{Fatigue test}

Figure 4 shows the relation between the maximum applied stress, $\sigma_{\max }$ and the number of cycles to failure, $N_{f}$, also defined as the S-N curves for the hybrid rods. 


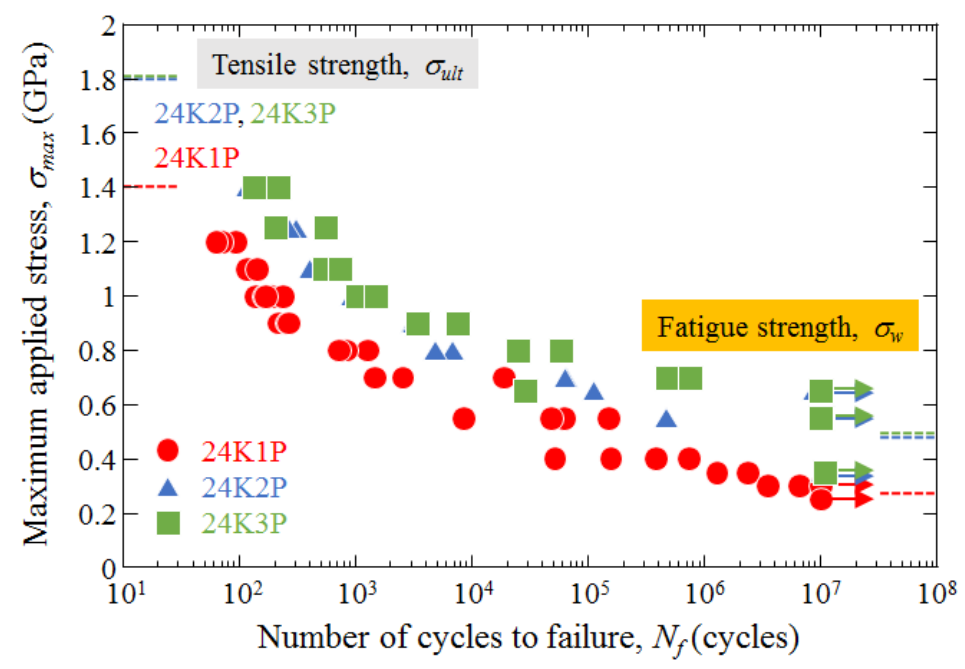

Figure 4: Relation between the maximum applied stress and the number of cycles to failure, S-N curves for the hybrid rods.

The fatigue properties of $24 \mathrm{~K} 3 \mathrm{P}$ and $24 \mathrm{~K} 2 \mathrm{P}$ were $30-70 \%$ higher than those of $24 \mathrm{~K} 1 \mathrm{P}\left(N_{f}=10^{4}-10^{7}\right.$ cycles). The present results confirm that the fatigue properties in terms of maximum stress increases with the volume fraction of the carbon fiber.

The fatigue strength at $10^{7}$ cycles, $\sigma_{w}$, for all-hybrid rods was less than $30 \%$ of ultimate breaking stress. The fatigue performance of the hybrid rods was significantly lower than that of conventional carbon fiber reinforced polymer matrix composites and steel rods.

\section{DISCUSSION}

\subsection{Tensile modulus and strength}

Figure 5 shows tensile modulus and strength for the hybrid rods, aluminum alloy, and high strength steel.

The tensile modulus, $E$, for the hybrid rods was approximately $81 \mathrm{GPa}$, which was similar to that for the aluminum alloy. Additionally, the tensile strength, $\sigma_{u l t}$, for the hybrid rods was approximately $1.69 \mathrm{GPa}$, which was similar to that for the high strength steel.

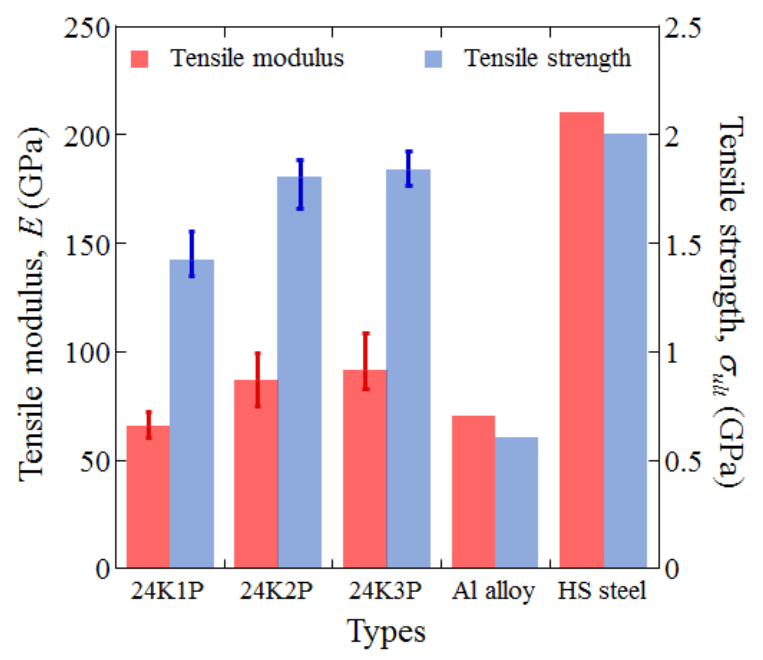

Figure 5: Tensile modulus and strength for the hybrid rods, aluminum alloy, and high strength steel.

The tensile moduli of the hybrid rods were calculated using a rule of mixture and laminate theory. The carbon fiber $(\mathrm{CF})$, glass fiber $(\mathrm{GF})$, and matrix $(\mathrm{M})$ are assumed to be isotropic materials with a modulus of 
$E_{C F}=230 \mathrm{GPa}$ [15], $E_{G F}=70 \mathrm{GPa}$, and $E_{M}=2 \mathrm{GPa}$. The volume fractions of the fiber (carbon and GFs) were found to be $V_{F}\left(=V_{C F}+V_{G F}\right)=64.33 \%$ for the $24 \mathrm{~K} 1 \mathrm{Prod}, 67.97 \%$ for the $24 \mathrm{~K} 2 \mathrm{P}$ rod, and $69.33 \%$ for the $24 \mathrm{~K} 3 \mathrm{P}$ rod, respectively.

The calculated results were found to be $E_{(C A L I)}=77 \mathrm{GPa}$ for the $24 \mathrm{~K} 1 \mathrm{P}$ rod, $E_{(C A L I)}=100 \mathrm{GPa}$ for the $24 \mathrm{~K} 2 \mathrm{P}$ rod, and $E_{(C A L I)}=114 \mathrm{GPa}$ for the $24 \mathrm{~K} 3 \mathrm{P}$ rod, respectively.

The void (V) is assumed for isotropic materials with the modulus, $E_{V}=0.1 \mathrm{GPa}$. The volume fractions of the void were found to be $V_{V}=10.18 \%$ for the $24 \mathrm{~K} 1 \mathrm{P}$ rod, $7.49 \%$ for the $24 \mathrm{~K} 2 \mathrm{P}$ rod, and $7.28 \%$ for the 24K3P rod), respectively. The elastic properties of the hybrid rods were also re-calculated using the rule of mixture. The estimated results were found to be $E_{(C A L 2)}=69 \mathrm{GPa}$ for the $24 \mathrm{~K} 1 \mathrm{P}$ rod, $E_{(C A L 2)}=92 \mathrm{GPa}$ for the $24 \mathrm{~K} 2 \mathrm{P}$ rod, and $E_{(C A L 2)}=106 \mathrm{GPa}$ for the $24 \mathrm{~K} 3 \mathrm{P}$ rod, respectively (The results are shown in Table 1).

The differences between the analytical and experimental results for the tensile modulus were $5.0 \%$ for the $24 \mathrm{~K} 1 \mathrm{P}$ rod, $5.9 \%$ for the $24 \mathrm{~K} 2 \mathrm{P}$ rod, and $13.7 \%$ for the $24 \mathrm{~K} 3 \mathrm{P}$ rod, respectively. The experimental results were found to be in agreement with the prediction.

The fracture stress of the CFRP was determined to be $4.90 \cdot V_{F}$ resulting in the values of $3.15 \mathrm{GPa}$ for the $24 \mathrm{~K} 1 \mathrm{P}$ rod, $3.33 \mathrm{GPa}$ for the $24 \mathrm{~K} 2 \mathrm{P}$ rod, and $3.40 \mathrm{GPa}$ for the $24 \mathrm{~K} 3 \mathrm{P}$ rod, respectively [11]. The estimated tensile strength, $\sigma_{u l t}(C A L)$, of the hybrid rods were $1.41 \mathrm{GPa}$ for the $24 \mathrm{~K} 1 \mathrm{P}$ rod, $1.91 \mathrm{GPa}$ for the 24K2P rod, and 2.19 GPa for the 24K3P rod, respectively (The results are shown in Table 1). The differences between the calculated and experimental results for tensile strength were $1.0 \%$ for the $24 \mathrm{~K} 1 \mathrm{P}$ rod, $5.7 \%$ for the $24 \mathrm{~K} 2 \mathrm{P}$ rod, and $16.2 \%$ for the $24 \mathrm{~K} 3 \mathrm{P}$. The experimental results of tensile strength were found to be in agreement with the prediction. The failure strains of the hybrid rods are also similar to that of the T700SC PAN-based CF (2.1\%) [15].

The hybrid rods indicated a carbon fiber-dominated behavior for the tensile properties in the longitudinal direction of the fiber reinforcements.

\subsection{Weibull distribution of tensile strength}

The results shown in Section 3.2 clearly indicate appreciable scattering of the tensile strengths for the hybrid rods. The statistical distribution of the fiber and composite strengths is usually described using the Weibull equation [16]. The two-parameter Weibull distribution is given by:

$$
P_{F}=1-\exp \left[-\left(\frac{\sigma_{u l t}}{\sigma_{0}}\right)^{m}\right]
$$

where $P_{F}$ is the cumulative probability of the failure of a hybrid rod at the applied tensile strength $\sigma_{u l t}$, where $m$ is the Weibull modulus (Weibull shape parameter) of the hybrid rod and $\sigma_{0}$ is a Weibull scale parameter (characteristic stress). The cumulative probability of failure $\left(P_{F}\right)$ under a particular stress is given by:

$$
P_{F}=\frac{i}{n+1}
$$

where $i$ is the number of hybrid rods that have broken at or below a stress level and $n$ is the total number of hybrid rods tested. Rearrangement of the two-parameter Weibull statistical distribution expression (Eq. 5) gives the following:

$$
\ln \left(\ln \left[\frac{1}{1-P_{F}}\right]\right)=m \cdot \ln \left(\sigma_{u l t}\right)-m \cdot \ln \left(\sigma_{0}\right)
$$

Hence, the Weibull modulus $(m)$ can be obtained by linear regression from a Weibull plot of Eq. (7). Weibull plots of the tensile strength for the hybrid rods are shown in Figure 6.

The Weibull modulus $(m)$ for the hybrid rods was calculated to be 23.77 for the 24K1P rod, 27.29 for the 24K2P rod, and 32.50 for the 24K3P rod, respectively (The results are shown in Table 1). The Weibull modulus for single carbon fibers were found to be less than 10 [17], and the Weibull modulus for the CFRPs was found to be less than 30 [18]. The Weibull modulus is higher for the hybrid rods than for the single carbon fibers and is similar to that of the CFRPs.

The Weibull modulus for the hybrid rods increased with a decreasing void content of the hybrid rods (as shown in Section 3.1). Even though the hybrid rods exhibited a carbon-fiber-dominated behavior for tensile properties in the longitudinal direction of the fiber reinforcements, the differences in the Weibull 
modulus can be attributed to the nature and distribution of the flaws present in the hybrid rods. It is well known that many defects, including voids, fiber breakage, and fiber misalignment, [19] can be introduced into these laminates during manufacturing and subsequent treatment. The presence of such defects in the laminates results in scattering of the tensile strength data.

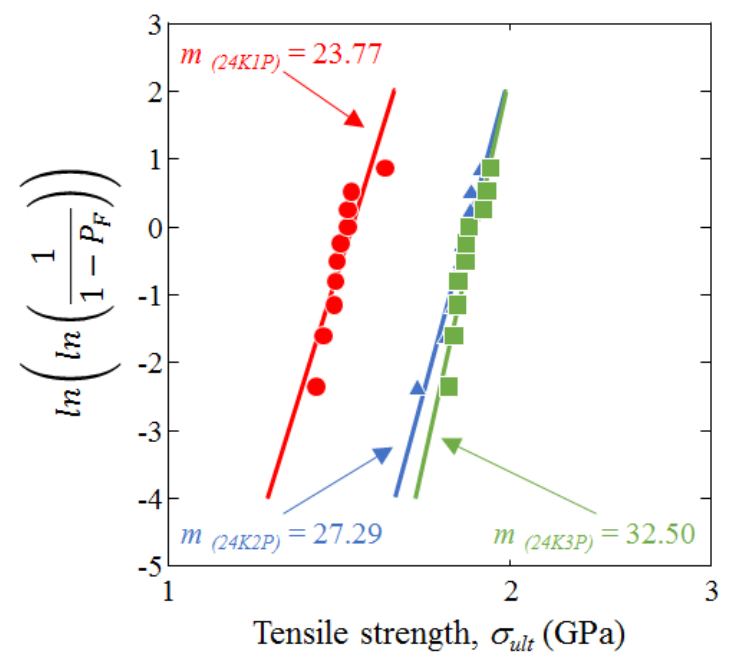

Figure 6: Weibull plots of tensile strength for the hybrid rods.

The Weibull modulus of tensile strength for the hybrid rods depends on the volume fraction of void.

The volume fraction of void for the $24 \mathrm{~K} 1 \mathrm{P}$ hybrid rod is quite high, and the strength differences between the samples strongly affect the void distribution. Therefore, the strength distribution for the 24K1P hybrid rod varies from lower to higher stress levels. As a result, the Weibull modulus of the 24K1P hybrid rod is low. In contrast, the volume fraction of void for the $24 \mathrm{~K} 2 \mathrm{P}$ and $24 \mathrm{~K} 3 \mathrm{P}$ hybrid rods is intermediate in value, and the excess strength affects the void distribution. Therefore, the strength distribution of the $24 \mathrm{~K} 2 \mathrm{P}$ and $24 \mathrm{~K} 3 \mathrm{P}$ hybrid rods is narrow. As a result, the Weibull modulus of the $24 \mathrm{~K} 2 \mathrm{P}$ and $24 \mathrm{~K} 3 \mathrm{P}$ hybrid rods is high. The hybrid rods with smaller volume fraction of void showed the narrow strength distribution.

\subsection{Fatigue properties}

Figure 7 shows S-N curves for the hybrid rods in log-log scale.

The power law model is given by

$$
\sigma_{\max }=a \cdot\left(N_{f}\right)^{b}
$$

where $a$ and $b$ are experimental constants.

The least squares fitting of the fatigue trends with a power law model as illustrated in Figure 7.

The intercept, $a$ and slope, $b$ are calculated to be $1.829,-0.1169$ for the $24 \mathrm{~K} 1 \mathrm{P}$ rod; $1.869,-0.0845$ for the $24 \mathrm{~K} 2 \mathrm{P}$ rod; and $1.947,-0.0843$ for the $24 \mathrm{~K} 3 \mathrm{P}$ rod, respectively (The results are shown in Table 1).

The results indicated the absolute values of slope, $|b|$, for the $24 \mathrm{~K} 2 \mathrm{P}$ and $24 \mathrm{~K} 3 \mathrm{P}$ rods were smaller than for the $24 \mathrm{~K} 1 \mathrm{P}$ rod, and strongly depended on the volume fraction of the voids. 


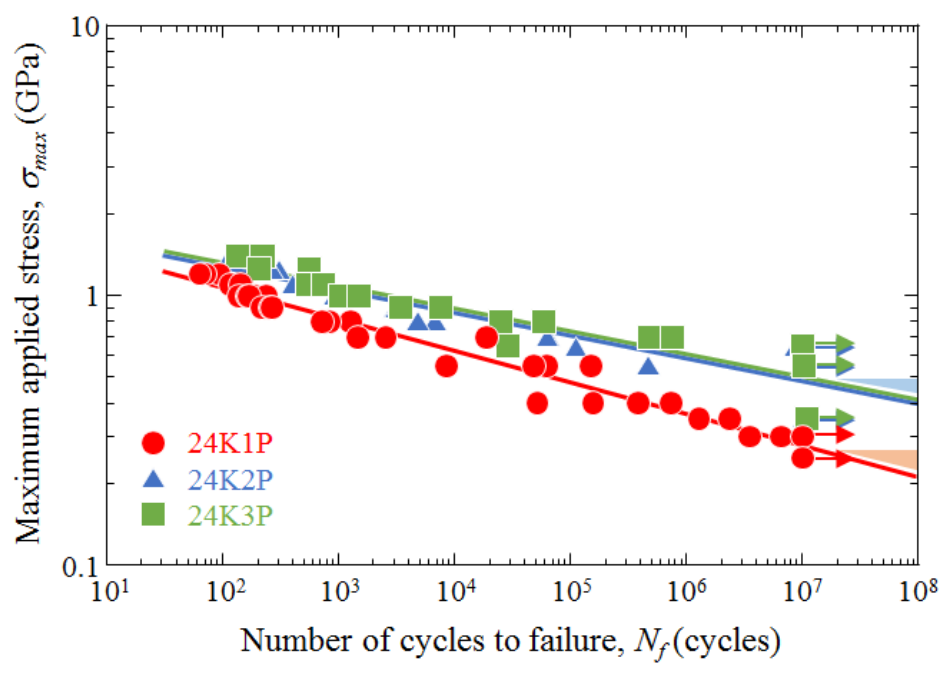

Figure 7: Maximum applied stress-number of cycles to failure, S-N curves for the hybrid rods in log-log scale.

\section{CONCLUSIONS}

The morphology of hybrid rods was investigated. Additionally, the fiber, matrix, and void volume fractions of hybrid rods were determined. The results of the tensile tests under static and fatigue loading of the hybrid rods are summarized as follows:

(1) The hybrid rods have a braid structure, with braid angles of $22.3^{\circ}(24 \mathrm{~K} 1 \mathrm{P}), 30.2^{\circ}(24 \mathrm{~K} 2 \mathrm{P})$, and $35.2^{\circ}$ (24K3P).

(2) Voids are clearly visible in the cross-sectional view of the hybrid rods, with the volume fraction of carbon fiber $\left(V_{C F}\right)$, glass fiber $\left(V_{G F}\right)$, matrix $\left(V_{M}\right)$, and void $\left(V_{V}\right)$ of $24.58 \%, 39.75 \%, 25.49 \%$, and $10.18 \%(24 \mathrm{~K} 1 \mathrm{P})$; $38.34 \%, 29.63 \%, 24.54 \%$, and $7.49 \%$ (24K2P); and 46.18\%, 23.15\%, 23.39\%, and 7.28\% (24K3P), respectively.

(3) The stress applied to the hybrid rod specimens was linearly proportional to the strain until failure, with a tensile modulus of $65 \mathrm{GPa}(24 \mathrm{~K} 1 \mathrm{P}), 87 \mathrm{GPa}(24 \mathrm{~K} 2 \mathrm{P})$, and $91 \mathrm{GPa}(24 \mathrm{~K} 3 \mathrm{P})$, respectively. The tensile strength was $1.42 \mathrm{GPa}(24 \mathrm{~K} 1 \mathrm{P}), 1.80 \mathrm{GPa}(24 \mathrm{~K} 2 \mathrm{P})$, and $1.84 \mathrm{GPa}(24 \mathrm{~K} 3 \mathrm{P})$, respectively. The failure strain was $2.18 \%(24 \mathrm{~K} 1 \mathrm{P}), 2.13 \%(24 \mathrm{~K} 2 \mathrm{P})$, and $2.08 \%(24 \mathrm{~K} 3 \mathrm{P})$, respectively. The tensile modulus and strength increases with an increase in the volume fraction of the CF. However, the failure strains are similar between the different types of hybrid rods.

(4) The Weibull modulus is 23.77 (24K1P), 27.29 (24K2P), and 32.50 (24K3P), respectively. The Weibull modulus increases with an increase in tensile strength and a decrease of the volume fraction of the voids for the hybrid rods. The hybrid rods with a smaller volume fraction of voids indicated a narrow strength distribution

(5) The fatigue performance in terms of the maximum stress increased with an increase in the volume fraction of the CF.

(6) The fatigue strength at $10^{7}$ cycles for all-hybrid rods was less than $30 \%$ of the ultimate breaking stress.

(7) The absolute values of the slope in a power law model of $24 \mathrm{~K} 2 \mathrm{P}$ and $24 \mathrm{~K} 3 \mathrm{P}$ were smaller than $24 \mathrm{~K} 1 \mathrm{P}$, and strongly depended on the volume fraction of void.

\section{ACKNOWLEDGMENTS}

This research was promoted by COI program "Construction of next-generation infrastructure using innovative materials $\sim$ Realization of safe and secure society that can coexist with the Earth for centuries $\sim$ supported by Japan Science and Technology Agency (JST).

\section{BIBLIOGRAPHY}

[1] GILBERT, R.I., MiCKLEBOROUGH, N.C., Design of prestressed concrete, New York, Spon Press, 
1990.

[2] BURNSIDE, O.H., POMERENING, D.J., Survey of experience using reinforced concrete in floating marine structure, In: Technical report SSC-321, Ship structure committee, 1984.

[3] WATSON, S.C., STAFFORD, D., "Cables in trouble. Engineered design and construction", ASCE, Civil engineering, v. 58 , n. 4, pp. 38-41, 1988.

[4] MEIER, U., "Carbon fiber reinforced polymer cables: Why? Why Not? What If?", Arabian Journal for Science and Engineering, v. 37, n. 2, pp. 399-411, 2012.

[5] GUSTAFSON, C.G., ECHTERMEYER, A., "Long-term properties of carbon fibre composite tethers", International Journal of Fatigue, v. 28, n. 10, pp. 1353-1362, 2006.

[6] CHANDRA DAS, S., NIZAM, M.E.H., "Applications of fiber reinforced polymer composites (FRP) in civil engineering", International Journal of Advanced Structures and Geotechnical Engineering, v. 3, n. 3, pp. 299-309, 2014.

[7] D'HOOGHE, E.L., EDWARDS, C.M., "Thermoplastic composite technology; Tougher than you think", Advanced Materials, v. 12, n. 23, pp. 1865-1868, 2000.

[8] Nagase ChemteX Corporation, Process for Production of Thermoplastic Cured Epoxy Resin with Transparency to Visible Light, and Thermoplastic Epoxy Resin Composition, United States Patent Application Publication, Pub. No. US 2014/0194590 A1, 2014.

[9] ASTM D792-13, Standard Test Methods for Density and Specific Gravity (Relative Density) of Plastics by Displacement, ASTM International, West Conshohocken, PA, 2013.

[10] NAITO, K., OGUMA, H., HAYASHI, Y., NAKAYAMA, T., et al., Fixing Structures of Fiber Reinforced Plastics Cables and its Fabrication, Strength Testing Methods, and Strength Testing Specimens, Patent, No. 2015-137928, 2015, (Japanese).

[11] ASTM D3039 / D3039M - 14, Standard Test Method for Tensile Properties of Polymer Matrix Composite Materials, ASTM International, West Conshohocken, PA, 2014.

[12] ASTM D3479 / D3479M - 12, Standard Test Method for Tension-Tension Fatigue of Polymer Matrix Composite Materials, ASTM International, West Conshohocken, PA, 2012.

[13] HUEY C.O.JR., FALEY, G.L., "Development of generalized 3-D braiding machines for composite preforms", Composites Engineering, v. 3, n. 3, pp. 209-213,215-218, 1993.

[14] ASTM D2734-09, Standard Test Methods for Void Content of Reinforced Plastics, ASTM International, West Conshohocken, PA, 2009.

[15] T700SC: Catalog for TORAYCA, Toray Industries Inc. (Toray), High performance carbon fiber Torayca (http://www.torayca.com/en/download/pdf/torayca.pdf), 2016.

[16] WEIBULL, W., “A statistical distribution function of wide applicability", Journal of Applied Mechanics, v. 18, pp. 293-297, 1951.

[17] NAITO, K., TANAKA, Y., YANG, J.M., et al., "Tensile properties of ultrahigh strength PAN-based, ultrahigh modulus pitch-based and high ductility pitch-based carbon fibers", Carbon, v. 46, n. 2, pp. 189-195, 2008.

[18] NAITO, K., YANG, J.M., KAGAWA, Y., “Tensile properties of high strength polyacrylonitrile (PAN)based and high modulus pitch-based hybrid carbon fibers-reinforced epoxy matrix composite", Journal of Materials Science, v. 47, n. 6, pp. 2743-2751, 2012.

[19] QIU, Y., SCHWARTZ, P. "Micromechanical behavior of Kevlar-149/S-glass hybrid seven-fiber microcomposites. II: Stochastic modeling of stress-rupture of hybrid composites", Composites Science and Technology, v. 47, n. 3, pp. 303-315, 1993. 